\title{
Autonomous vehicles and impacts of the wider insurance industry
}

[Institute and Faculty of Actuaries, Sessional Event, London, 28 October 2019]

Mr V. Badal, F.I.A. (opening the event): My name is Veekash Badal from Milliman and I am the Chairman of the Emerging Risks from Autonomous Vehicles Working Party. It is my pleasure to open this sessional meeting today to discuss autonomous vehicles and what they will mean in terms of the wider insurance industry.

This is an area that is rapidly developing. The Working Party is made up of individuals from different parts of the industry. We are looking at the opportunities and risks that will arise from autonomous vehicles. The Working Party will continue to investigate these issues and communicate on them as they arise over the next few years.

The talk this evening is broken down into two parts. The first part will cover the development of autonomous vehicles and the second part will look at the impact on the insurance industry. The chairman of our discussion is Kevin Wenzel, who is Chief Financial Officer of LV= General Insurance. He is a member of the General Insurance Board of the Insitute and Faculty of Actuaries (IFoA) and has helped to develop the IFoA's response to a number of consultations on this subject.

The first speaker is Neil Fulton, who is the Chief Operating Officer at the Connected Places Catapult. Neil was a Programme Director at the Transport Systems Catapult, where he led many pieces of connected and autonomous vehicles research, development trials and demonstrations. Dave Baldwin is Head of Data Insight at Thatcham Research. Dave developed the latest iteration of Thatcham's "Claim of the Future" model, projecting forward the effect of new vehicle technology on future accidents and insurance results.

Mr N. Fulton: Connected Places Catapult was created in April this year following the merger of the Transport Systems and Future Cities Catapults. We are here to grow jobs and the economy. We do that by connecting people and goods, and improving the places in which they flow. We take part in a lot of collaborative research and development projects that ultimately benefit the organisations that we work with across industry, academia and government. Many of you will be familiar with the Gartner Hype Cycle, a yearly graphical snapshot to represent the maturity, adoption and social application of specific technologies through five phases. Despite the fact that this has been criticised for a lack of evidence, I am going to use it this evening to try and demonstrate a couple of my points. See Figure 1.

Autonomous vehicles made their way onto the curve in 2010. In 2013, when I started at the Transport Systems Catapult, they had moved quickly through the innovation trigger and they were very close to entering the peak of inflated expectations. By 2015, they had reached that peak, and a couple of years later had begun to descend into the trough of disillusionment.

Last year, something interesting happened. Gartner decided to split autonomous driving into levels four and five of autonomy. At that moment, level-five autonomous vehicles started again in the innovation trigger, only slightly ahead of light cargo delivery drones. It made me think that if, today, level-four autonomy has made it through the slope of enlightenment, then it will not be 


\section{Gartner.}

\section{Gartner Hype Cycle for Emerging Technologies, 2014}

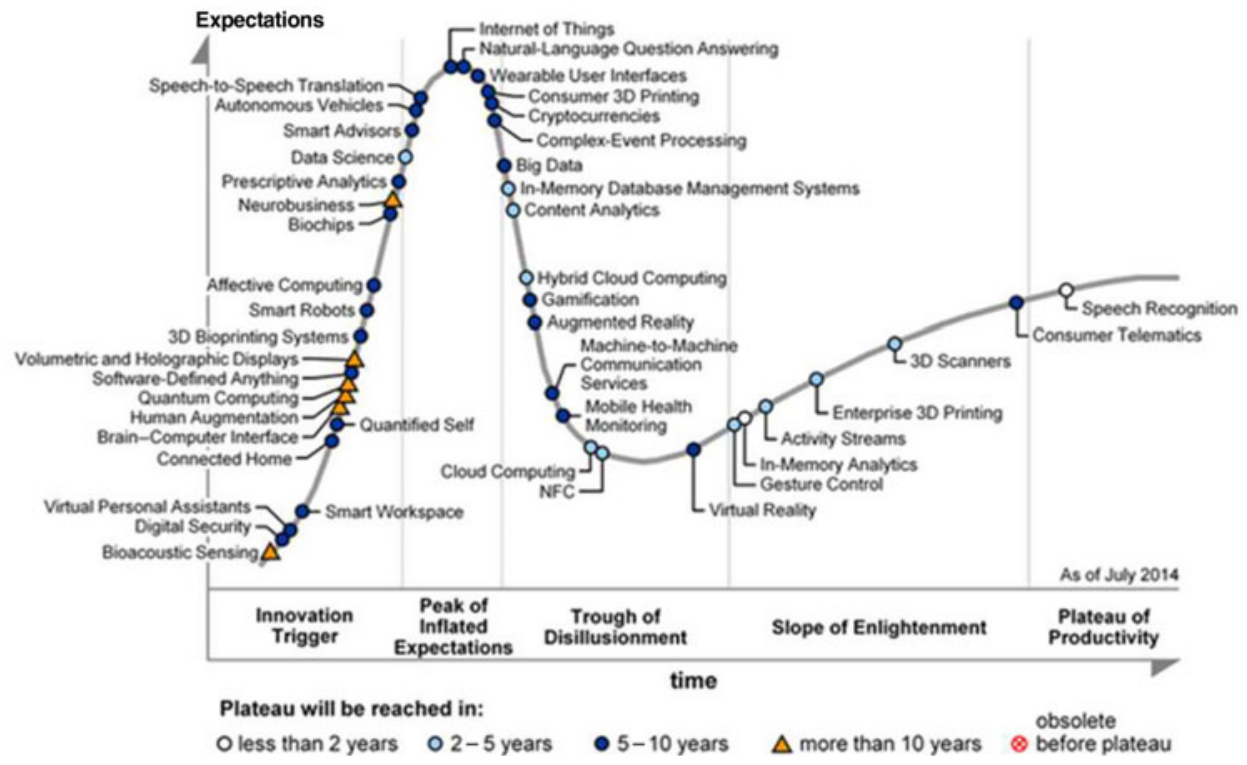

Figure 1. Gartner hype cycle for emerging technologies 2014.

long until we are in the plateau of productivity. If that is the case then all the challenges are presumably fixed. Challenges with safety and security of these vehicles must be pretty straightforward. This brings me onto the drivers. We can summarise this with the "ACES" (Automation, Connectivity, Electrification, Sharing) acronym. Many of the car manufacturers now use this acronym to describe their business models, which is hardly surprising given the speed at which the industry is evolving. First, if we look at automation (A), the main driver is safety. To put the issue in perspective, the number of people killed globally in cars every day is approximately the same as the number of people who would fill ten Boeing $747 \mathrm{~s}$. If we can remove the errors that are made by humans, then we can save lives. I presented at a conference a few years ago and in the Q\&A session, somebody said to me, "I like driving my E-type Jaguar around the country lanes at the weekend. Why should I even consider going for an autonomous vehicle?"

There was another argument on the other side of the room saying, "Actually, if we can deploy these vehicles and we can remove the safety element, then why wouldn't we do that immediately? And if that technology exists, why don't we do it immediately?" My fear is that there is very little guidance around the legislation for automation, and this clearly depends on the skills of the programmers of the autonomous driving system itself. As an example of the challenges for that, my wife's car is fitted with advanced emergency braking. It always slams the brakes on when we go under the same bridge in Milton Keynes, for reasons unknown to me. If we look at connectivity (C), about $90 \%$ of new cars are already connected. But they are really connected to infotainment and for data collection for fleets and helping with diagnostics. The possibility of them being connected to make driving decisions, particularly in the event of a safety incident, is currently not feasible. Next steps will include connectivity to infrastructure to help inform traffic patterns. The consumption of data through connectivity and managing the data on the vehicles and the energy required to do that presents challenges that the automotive industry has not had to deal with in the past. The "E" stands for "electrification". Clearly, we are not here to talk about electric 


\section{The Autonomous Car}

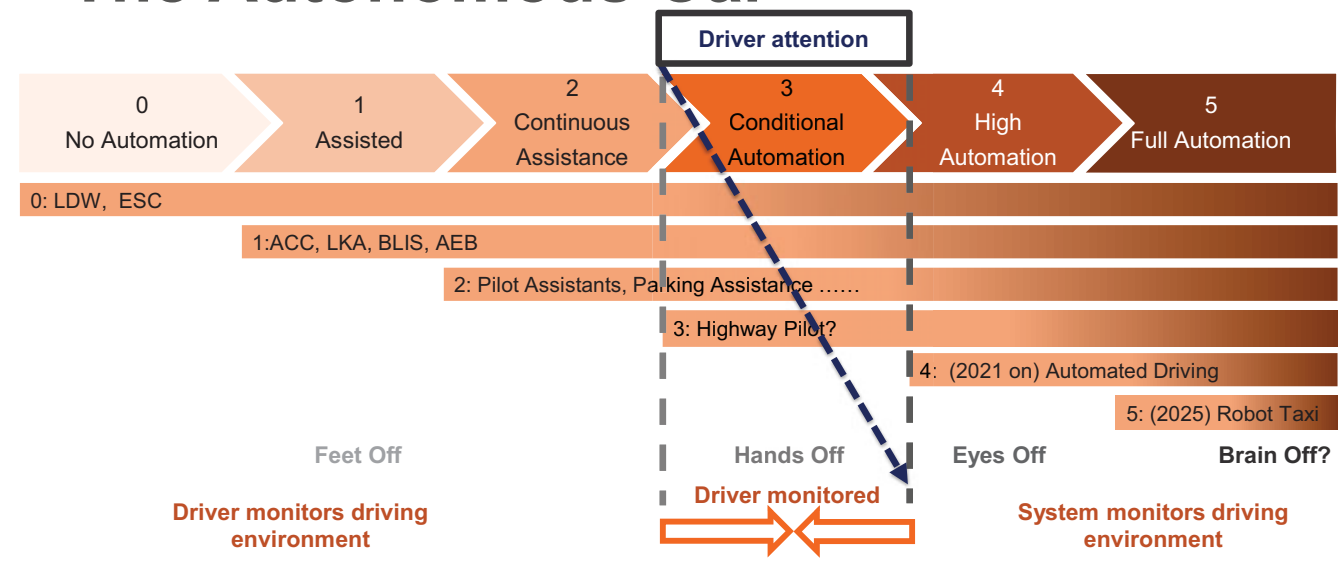

11 May 2020

Figure 2. The autonomous car.

vehicles, but I believe they will be an important feature in the development of autonomous vehicles. I think when we are not driving, that is, when we are being driven, we will expect silent transmission-less transport. I believe that tipping point for the adoption of electric vehicles on a grander scale is probably only 2-3 years away. As an example and a guide on this, I look at organisations like the enormous $\mathrm{BP}$ organisation that has recently purchased Chargemaster for the deployment of electric vehicle charging posts around the UK.

The "S" within "ACES" stands for "sharing", or "services" sometimes. Here we are talking about the digitisation of transport, the concept of mobility as a service as well. It is interesting that the traditional silos across transport are beginning to merge. The car manufacturers, the bus operating companies and leasing companies, for example, are all referring to themselves now as "mobility services providers". Remember that for $95 \%$ of its life, the average car is parked, unused. Let us not forget that one of the main drivers here is productivity. The UK automotive industry has struggled during the '70s, ' 80 s and '90s. More recently, it has seen something of a resurgence, in particular in manufacturing but also in some of the specialist or niche sectors. They lend themselves very well to the development of autonomous control systems in autonomous vehicles. There is an opportunity now to be global leaders in some of the advanced technologies that we refer to here, but that depends on government appetite, on industry and academic engagement. We are in a global race and the competition is fierce.

Mr D. Baldwin: ACES is really important from the point of view of the whole picture for autonomous vehicles, and vehicles in general, as they develop. I am going to be explaining the levels of automation. We often refer to the Society of Automotive Engineers' levels of automation and there is a huge amount of media comment about it. Very often, it is not explained exactly what these things mean and also the challenge is that we do not believe in them. We will talk through what we see as automation and how we need to think about it.

Figure 2 shows the five levels of automation. On the left-hand side, we have automation in terms of low-level functions, systems that are there for drivers to be supported in the driving environment, for example, adaptive cruise control (ACC), lane keep assistance (LKA), blind-spot systems (BLIS) and autonomous emergency braking (AEB). Single functions in that level-one assistance will be there to support the driver in their driving tasks. Next is Continuous 


\section{Autonomous Vehicles on the Road}

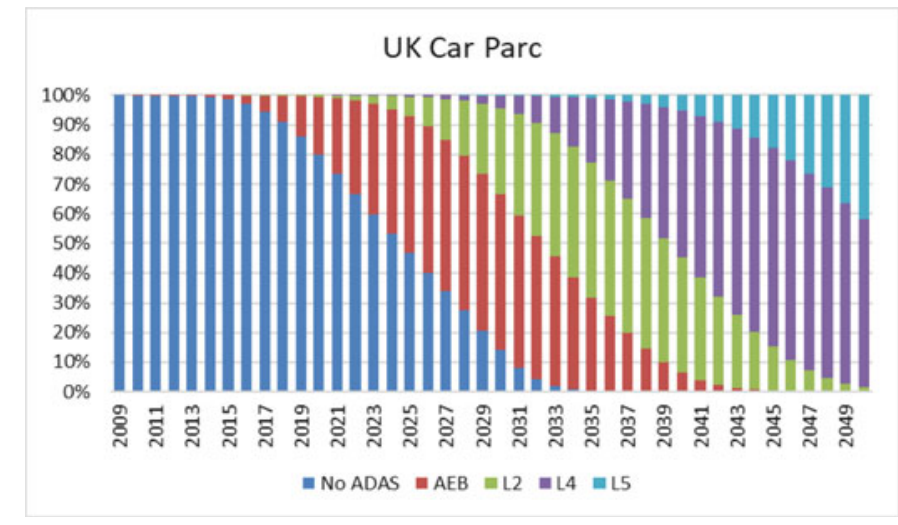

Today $-10 \%+$ AEB

5 years $-5 \%$ of Fleet

have L2 assistance

10 years $-3 \%$ of Fleet

have L4 automation

20 years $-50 \%$ of Fleet have

L4 automation, 4\% L5

30 years - Almost all Fleet

have some automation

Mixed driving fleet for

foreseeable future

28 October 2019

Figure 3. Autonomous vehicles on the road.

Assistance, where we have combinations of these systems. For example, a pilot system will bring together adaptive cruise control and lane-keeping so you can stop having to worry about keeping your speed monitored but, equally, the car will keep you in lane. You start moving into a position where you are there when the car needs you, but in the right circumstances the car can provide support in your driving task.

With Conditional Automation, the driver is responsible for monitoring the system when the car takes control. This is where we start to get worried. As we move into the higher levels of automation and into the automated and increasingly autonomous vehicles, the system is beginning to take over the role of the driver. Under the right conditions, the system monitors the environment with the driver becoming a monitor. However, in Conditional Automation, the driver is still responsible for making sure the system is doing what it should be doing and is also responsible for being there when the car can no longer deal with the external conditions. Today many cars have the "feet off" function. I have adaptive cruise control in my car. I do not use the pedals very much because my car will speed up and slow down for me. When I come to roundabouts, I get worried. I put the brakes on. I use the pedals. But most of the time, on motorways, I can do the work of steering without having to use my feet. Increasingly, as we move into Conditional Automation, you can take your hands off the wheel for a bit longer. You do not need to engage with the driving task as much.

As we move into High Automation, from 2021 potentially, we have automated driving where you can start taking your eyes off the road. Not always, but the car will allow you to do that for a period of time.

Finally, you get your robot taxis; you can turn your brain off. So, get in your car, tell it where you are going, you can go to sleep and the car will take you there. It will wake you up when you get there.

That is our nirvana, but probably we will not reach it in 2025. There may be some things which will be out there in 2025, which will feel like driverless, but they will not be able to drive everywhere. One of the key things to recognise is that "High Automation" functions will only work in certain domains. It might be in a parking environment or it might be a highway or urban 
environment, but it is not going to get you from Land's End to John o' Groats without you needing to be involved at some point.

In this middle ground before high automation, we have a problem with driver attention. As cars become more capable, the driver becomes more confident that the car can do the job far better than it is designed to. At some point, they think they can go to sleep. Have a look for "Tesla driver sleeping" on the Internet or YouTube, and you will see examples of Tesla drivers - the Tesla is a level-two vehicle, not a level-three vehicle - where drivers have been filmed asleep at the wheel. The steering wheel needs some human resistance, so some drivers are bright enough to tie their hands to the steering wheel to keep them from dropping out of the system. It is more a comment about the Tesla drivers than the Tesla system. Our big concern with Conditional Automation is that the driver drops out of the loop and the car is unable to deal with everything. When it needs you, you are not there for it.

Right now, there are no level-three systems on the road in Britain, only level two. Vehicles where the driver is still responsible are "assisted vehicles". "Automated driving" is where the cars will be able to take over control for a period of time. Then we move into "full automation" or "autonomous", where the car can do all the work. The latter is quite a way off, but the car being able to do automated driving is relatively near for some systems. When we look at how this is going to deploy on the road, it is tricky. New vehicle registrations of electric vehicles are going to be very high in the next few years as tax breaks and other initiatives come through, which incentivise new technology take-up. See Figure 3.

Unfortunately, we have a car park of cars that are being kept for longer and longer. On average, a car may be kept on the road for 15 or 16 years now, which means that it takes a long time for these new cars to make a big impression on the car park. Right now, about $12 \%$ of the car park has got AEB. In 5 years, if we assume that the level-two systems come through, maybe $5 \%$ of the fleet will have level-two assistance. In 10 years, maybe $3 \%$ of the fleet will have level-four automation.

If we move ahead 20 years, perhaps $50 \%$ of the fleet will have level-four automation with some level fives coming in. Even if we wind forward 30 years, we are still talking about a fleet that is going to be mixed. When I say "mixed", those level-four vehicles may just work on the motorways for some of the earlier systems. We have got some challenges ahead in terms of mixed fleet. It is going to be a challenge for pricing.

Figure 4 is a picture of an autonomous vehicle, and all the functionality and sensors it is going to have to have. All the way around those vehicles, it is necessary to have sensors: a variety of LIDAR, RADAR and cameras. We are going to have to have ultrasonic sensors and 360-degree cameras. There is a lot of kit on there. I had the radar replaced on my car recently and that was $£ 1,600$ just for the part. For other manufacturers, it can be double of this. Whilst we may see a reduction in the frequency of claims, this will go hand in hand with a significant uplift in the cost of the claims coming through. We have challenges in fitting, in calibrating the systems and a whole range of new challenges coming into the industry to ensure that the repairs are done effectively by appropriately trained engineers.

There is a lot of uncertainty over claims and the insurance cost savings on the damage side are still up in the air in terms of whether any cost savings will emerge on damage claims. It is not all rosy in terms of how things are going to come through.

The Chairman (Mr K. P. Wenzel, F.I.A.): For our discussion, we have Niall Edwards, a partner at Kennedys and a specialist in motor litigation. He also lobbies, presents and advises on autonomous vehicle technology. He has drafted responses, articles and papers in relation to these topics. Zvi Ebert is a commercial pricing manager at ERS. A keen logician and strategist, he continues to closely follow developments within the InsureTech and FinTech space, with the intention of bringing this innovation development mindset to established companies in the profession. Lastly, we have Chris Jones, who is head of commercial automation document services at Admiral. I am going to ask the first question in this second session: Niall, from your point of view, what exactly is the current legal situation with regard to these vehicles? 


\section{Autonomous Vehicles - Cost of Use}

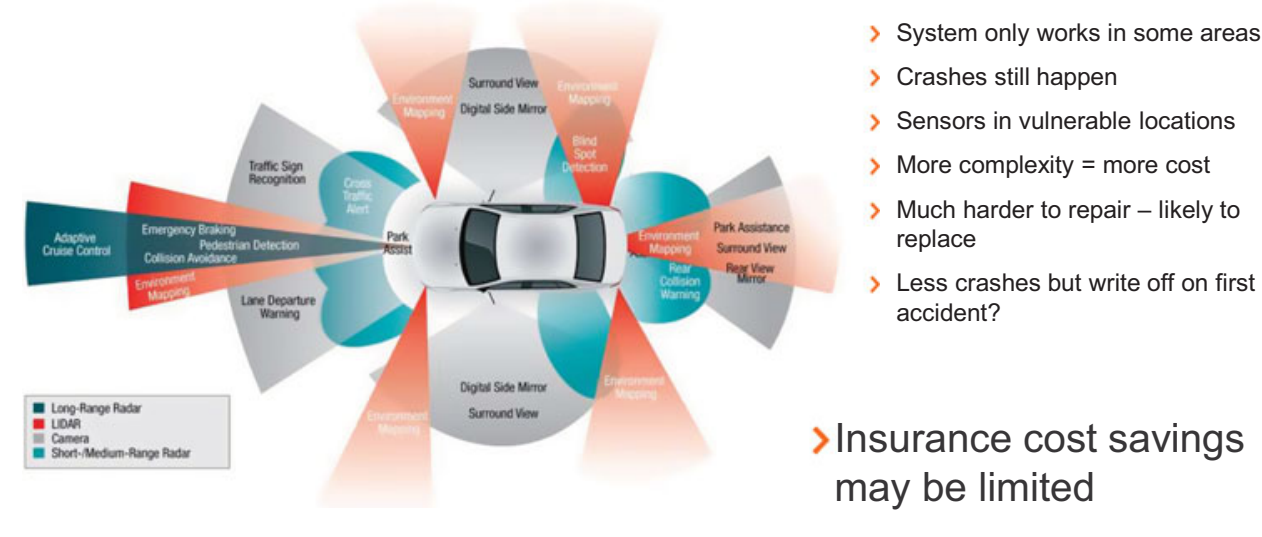

28 October 2019

Figure 4. Autonomous vehicles - cost of use.

Mr N. Edwards: The thing to remember at this stage is that whilst we have got the Automated and Electric Vehicles Act, it is not yet operational. Section one of the Act requires a list of all tier four and five vehicles to be kept by the Department of Transport. As Dave (Baldwin) has outlined, we are not there or anywhere near there yet. The first point is that the legislation is in place, sort of, for the future, but it is not yet operational.

The second point to make is that we do, of course, have assistive systems already, helping people park, helping people with lane assistance and so forth. I am a defendant motor lawyer. Surprisingly few cases come to us where there has been an accident involving the use of one of these systems and it has malfunctioned. It occasionally happens, but the point with those at the moment is that the driver is responsible even if the assistant system is taking the lead. The driver is there and is on the wheel.

The third point is that even when this legislation comes into force, we have got this very thorny issue of handover and hand back. We are not talking, in the foreseeable future in the UK, about no steering wheel, "Mr Johnny Cab" and that sort of thing. We are talking about people having to maintain some concentration on the road, on the HUD (Heads-Up Display), and all the issues, evidentially, causatively, with that. How do you hand over? When is it reasonable to hand over? How do you hand back? How can you hand back? How much time do you need to hand back from an autonomous system? All of that is yet to be explored. That is where we are at the moment. It is going to happen, but it has not really happened yet.

The Chairman: Chris (Jones), from an insurance perspective, what keeps you awake at night in terms of things like these connected vehicles? Is there anything that is worrying you about them?

Mr C. R. Jones, F.I.A.: Having taken the decision to move to a motor insurance company 4 years ago, I am less worried now than I was back then about moving into what could be a declining industry. I asked a couple of claims colleagues this morning if there was anything that kept them up at night. One answer was "Not in my lifetime" and the other was "FOMO - Fear of Missing Out", a sort of tweak to the business model. What does concern me is the transition risk. If you think about the change in mix of the fleet, as Dave (Baldwin)'s presentation showed, coupled with a large amount of legislative and regulatory uncertainty, I think that risk is quite real. There was a 
presentation recently for the Transport Research Laboratories that stated that there is more technology going onto vehicles in the next 5 years than there has been in the last 50 years. They showed a video of an old Citroen, which was fully automated back then. If you think of the improvements in vehicle safety that we have had, it is quite a stark claim to make. When you throw in optionality, in terms of what consumers will want on their vehicles as well, that makes it very difficult for insurers to price and to underwrite and for handlers to tackle the liability. On the claims side, it is the race to capture. It is that first notification of loss, the potential shift in power from an insurer looking after their customers to manufacturers getting there first, introducing their supply chain, and insurers losing that ability to control costs. The ratio of the sum of costs for a vehicle versus the retail value is ever-increasing. Manufacturers are keen to keep vehicles on the road longer and insurers are in a difficult position. It is the opportunity to think about their strategies now while the legislation and manufacturers are starting to introduce these vehicles. It could be a frictional path.

Mr M. G. White, F.I.A.: As I listened to the first parts of the presentation, I had a vision of motoring costs going up massively. Is that plausible or am I missing something?

Mr Z. Ebert: If we look at Apple and mobile phones, or Google and things where the companies own the whole channel, the whole chain of distribution. If vehicles become a service and we see it as a mobility service where the manufacturers start owning everything, we will not necessarily buy the car; the car will be there when you need it, if you need it. You will order it for that purpose. That will change the cost structure and also challenge the insurance companies who have $£ 18$ billion in the UK.

Mr White: That sounds like a "yes" to me.

The Chairman: There is also the injury side. Does anybody want to comment on some of the changes that we are likely to see?

Mr Edwards: The first point is not just with autonomous systems but with electronic systems and advanced technology in cars. The costs of repair to vehicles are starting to escalate. Curiously, low-end injury - which is most injury due to the advancements in materials, technology and everything else - is being tariffed, being capped and will be reduced. Certainly, low-end whiplash is going to be reduced in the years to come. The irony is that the cost of repairs or replacing parts of the vehicles is going to dwarf low-end injury in the future. That is readily foreseeable. How that will balance, I am not sure. The cost of the vehicle damage, even moving forward and allowing for commoditisation, is going to be quite expensive versus the injury cost. We are already seeing far less serious injury in vehicles in road accidents in this country.

Mr Fulton: The traditional model of motoring will change beyond all recognition. When I was 17 , the first thing I wanted to do was to pass my driving test and buy my first car, and that is what I did. I think we are starting to see a lot of change there. The whole model is changing and vehicle ownership models are clearly changing beyond all recognition. The leasing companies are offering shorter and shorter term leases to accommodate that.

The idea of having a vehicle that we own and it sits on the driveway or in a parking place for $95 \%$ of its life will change. Car sharing and car clubs will become much more prevalent. The traditional models will start to change fairly rapidly. One thing that has not been explored is generational change. If I look at my children, the way that they plan to use transport and vehicles will change beyond all recognition in the years to come. Will my children's children take a driving test? I think it is probably unlikely.

Mr B. Gedalla: Much of what we hear about the future of autonomous cars seems to be around the car as a utility. But where do you see the future for high-performance cars? Do you see people only taking driving tests because they want to drive high-performance vehicles and then only driving them on tracks? Is that the future of the high-performance car?

Mr Edwards: Yes. I think ultimately that is where we will get to. I do not think it will look anything like it does today. If you are one of those car manufacturers, Aston Martin or 
McLaren or somebody like that, clearly you are still trying to focus on your unique selling point. I think that is going to get harder and harder for those organisations.

Mr Jones: It also depends where the cars are being driven. I have just come back from a holiday in South Korea and I was amazed as I drove a 3-hour journey north to south. I thought "crikey there is a lot of infra technology on the roads". If you think about where I am living at the moment in Wales, in terms of the amount of investment that is needed to make sure that the roads are capable of taking a fully automated vehicle, I think we are a long, long way off. We could see a dual system arising.

The Chairman: You touched on Tesla and we do not want to call out one manufacturer, but I am mindful we have had the recent Smart Summon feature. It does seem to be causing an awful lot of havoc for the general public. I was wondering whether you could reflect on what that means and what it looks like for the public when they see this.

Mr Baldwin: Smart Summon is simply a function that Tesla introduced to allow Tesla drivers to get their cars to come out of their parking bay and drive to them rather than needing to walk to their cars. Unfortunately, as I mentioned before, Tesla drivers then wanted to test it to its limits. You pick a busy car park and say "Bring my Tesla to me" and then watch it try to negotiate human drivers, which is not great in terms of capability. This is part of the challenge; people are expecting a car to be fully functional. They want a Herbie, the car that can think for itself. It is not that good yet. And this is the challenge. When we see people talking in the media talking about driverless cars, we need to remember there aren't any on the road today. Tesla is being used as the example because Tesla is, to some extent, ahead of the game. They have also implemented their over-the-air updates. They can change the functionality of their car overnight. They introduced "Ludicrous Mode" that reduced the time to go from 0 to $60 \mathrm{mph}$ from five to just under 3 seconds with a software update.

As an insurer, you are insuring a car that had a certain performance yesterday and overnight it has changed that capability. Tesla also introduced changes to extend their range when there were the Californian fires a few years ago. For the lowest-end Teslas, they put out a range-extender so that people could get away from the fires if they needed to. This is the functionality of your vehicle changing with software and not just with the hardware. This is a fundamental change in the nature of vehicle risk. But the fact that Tesla is doing this is important because we get to ask the questions now rather than in a few years' time. It is also important because what Tesla is doing is laying down the gauntlet to other manufacturers. What we are seeing is other manufacturers having to respond to this and introduce their own electric vehicles. Probably we are seeing the deployment of automation being accelerated, but by manufacturers who are not software developers. They are people who have made cars for 100 years who are now trying to introduce some of this technology. It is a completely different approach that the two sides are coming to. Hopefully the right answer will emerge eventually. But for now, what we are seeing is a lot of examples of people who should not be driving cars who are driving Teslas. It makes for good YouTube examples and it demonstrates the dangers of providing humans with this technology.

Mr T. A. G. Marcuson: A slightly mischievous question. A lot of the descriptions are about the clever features that are being put in the high-tech cars to help them drive, but is there any technological development to avoid being hit by non-tech cars? Because if you look at the weight of cars that you are showing in some of those statistics, it looks like your biggest danger is sitting in traffic and that an unautomated or unassisted car hits you. Is there any research on technology to reduce the risk or reduce the damage?

Mr Baldwin: One of the fundamentals going on in the background is collision avoidance technology. We talk about automatic emergency braking, but we have also got automatic emergency steering. In other words, if a car is coming towards you and you can see it is about to hit you, then your car will be able to swerve away. Automated driving is about driving safely and not getting too close. There are humans on the road, there are other cars and unexpected events happen. You need background systems to get you out of trouble if you do get too close. Most systems will 
be there if people are going to ram you. Unfortunately, they won't be able to stop an accident happening. Some Audis have automatic braking if they detect that the car behind is getting too close. It will put up some warnings to make the car aware that it is about to hit you. Some of this technology is already in vehicles today. It is a case of how active that needs to be, but it is certainly going to be there.

Mr Fulton: We are involved in a research project at the moment with a couple of test houses at Cosworth, IDIADA, a university and a couple of small and medium enterprises (SMEs) to do a "cooperative ITS project". It has an acronym called "MUCCA". It is a very early-stage project to look at how two vehicles might cooperate to inform each other of an obstacle ahead. I think that sort of technology and the cooperative Intelligent Transport System (ITS) approach is in its infancy. It depends on good connectivity and advanced features within the vehicle, which are hugely energy consumptive. We are some time away from those systems operating safely.

Mr Ebert: When you are avoiding one risk, you are probably creating a new risk, and that is the secondary impact. The cost of the cars themselves, which have been noticed to be increasing by insurers, wasn't foreseen by creating sensors and those kinds of things. It will be the same if a car is moving out of the way to avoid one risk in terms of what it is knocking over to do that. Those types of question are still a long way from being resolved.

Mr S. Fisher, F.I.A.: How well has the industry - especially at the more autonomous end of the technological spectrum - developed its thinking around the key ethical questions raised by this new technology? For example, in a real-life situation where some other vehicle (or driver) behaves irrationally or unexpectedly, how should an autonomous vehicle assess the relative value of the lives of the people in the vehicle versus the lives of the pedestrians that may have to be hit in order to avoid a collision with the other vehicle? If you cannot protect one individual or group without risking harm to others, then who should be prioritised in this decision-making? And does the decision change according to the age or any other characteristics of the individuals involved? These are areas where unavoidable ethical decisions will need to be made. Those developing this new technology cannot simply opt out of such ethical questions. Has this thinking been developed? And if not, what needs to be done in order to address those questions?

Mr Baldwin: My first reaction to the ethical question is: if the car gets itself into a situation where it is having to make those decisions then it is not a very good automated car because the car should remain safe at all times. Obviously, we have human drivers on the road and probably they are the ones causing the challenge. We are a long way off allowing machines to make those ethical decisions. We may be capable of coming up with the logic of doing it, but in terms of legislating for it we are quite a long way from being prepared to give that decision to a machine. I would rather focus on worrying about near misses and why the car gets into the situation in the first place. If we are worrying about automated vehicles killing people, we have probably let them get too aggressive because they really should be driving safely. A lot of the reasons for accidents happening and people getting killed are because people are not driving safely and are not driving at the speed limits and so on. The reasons why many accidents happen should be taken away by automated vehicles.

Mr Edwards: The reason I have been employed for 20 odd years is because human drivers constantly make very bad decisions. I have overheard conversations in terms of the ethics, not so much the vehicle making the decision with the Artificial Intelligence (AI) but a setting on the inside of the vehicle to prioritise who you protect most inside the vehicle in a collision. Do you protect the driver? Do you protect the people in the back? Or the front-seat passenger? Or a combination thereof? Who is safest in the vehicle? They can already do that and there are sensors that can adjust. The technology is there to reconfigure the insides of the car to absorb an impact in a certain way. For instance they can be reconfigured to prevent a lot of damage to a pedestrian in the front of the car and so forth. That is where we are with one ethical issue. I entirely agree with Dave (Baldwin) about finding yourself in a position where is it two dogs, a nun and an old person, or three children that are impacted? 
Ms L. J. M. McMaster, F.I.A.: There was a comment earlier about how, with the damage to cars, they might be more likely to be written off sooner and obviously this would increase costs. Over the time frame of the replacement of vehicles, the ideas of reuse and recycle and the circular economy are going to be much bigger and stronger and will change the way the cars are manufactured. Is it something that car manufacturers are starting to recognise and talk about, and if so how much? Do you think there is a chance that the way they design cars to stop them being written off will make them cheaper and easier to repair, hence bringing costs back down?

Mr Baldwin: Part of the challenge in the way that cars are being designed is passive safety protection. In the event that an accident happens, the impact is absorbed by the vehicle rather than by the passengers. By having active safety features to stop accidents, we will see cars having fewer accidents. You will see a car being on the road for a lot longer because it does not have a crash. The question is, when it does have a crash, does the damage caused just end up as a right off so you keep your car until the first crash? We have talked about sharing. Do you move to a situation where for somebody to come up with a lot more technology, you never actually own the vehicle, it is something you lease? If you look up "Care by Volvo" on the Internet, you can see there are already schemes where you do not really own the car but you have all the benefits of owning it. Volvo Cars have the opportunity to refurbish and do what they want with it after 2 years. They can make sure that it is more environmentally friendly. We are still at the early stages of seeing any of these benefits coming through. That is part of the challenge. We can talk about where we will be in 20 years' time but, right now, we are at the change point. We are starting to see some of the negatives, but have not yet seen all of the positives coming through.

Mr Jones: In the near term, total loss and the salvage model is something that sits alongside the assumption that you will repair all cars. Some of the electric vehicles we have and the cost of replacement batteries, they are almost making cars a write-off from the start. When you put that into a salvage yard and when you work out whether those parts can be broken up or where the vehicles can be sold on, that is almost a cost-control element for the insurer to manage these rising costs for the manufacturers. Thinking about total loss avoidance schemes, where you encourage manufacturers not to charge $£ 3,500$ for a Hyundai part but look at an equivalent original equipment supplier (OES) part instead of an original equipment manufacturer (OEM) part that is

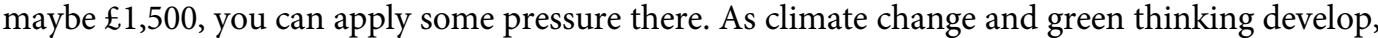
there is much more pressure to recycle, alongside gaining trust that the recycled parts are of a correct safety standard.

Mr Ebert: We are also seeing that, even with the high-performance cars at present that are petrol-led, if you damage one panel then you need to replace the whole side of a car. That is happening now and we are seeing claims like that. As production gets cheaper, repair will get more expensive through 3D printing or creating cars as one piece. Repair will mean total write-off of that vehicle. I do not see manufacturers moving towards a green view unless they are forced to. It would be difficult to make them to do that.

The Chairman: We now have two very short presentations. Deborah Newberry and Andy Goldby are going to present first. Deborah Newberry leads Kennedys' intellectual innovation, running successful fault leadership campaigns and public affairs initiatives. Deborah has undertaken global research projects on behalf of clients on a broad range of issues including autonomous vehicle technology.

Andy Goldby is the Chief Actuary at The Floow, which is a device-agnostic telematic service provider. Andy is an Autonomous Vehicles (AV) Working Party member with interests in data science and motor rating.

Ms D. Newberry: The actual technology and what it can do is a vital component to making all of this a reality. But the other part of this is consumer acceptance, and that is the focus of my talk.

Figure 5 is taken from a report prepared by KPMG and shows a readiness index which measures countries around the world against four key pillars that include consumer acceptance. It includes the actual technology and the innovation as well as the infrastructure and the policy 


\section{Who is winning the race: national profiles (2019)}

\begin{tabular}{|c|c|c|c|c|c|}
\hline $\begin{array}{l}2019 \\
\text { Ranking }\end{array}$ & Country & $\begin{array}{l}\text { Policy and } \\
\text { legislation }\end{array}$ & $\begin{array}{l}\text { Technology } \\
\text { and Innovation }\end{array}$ & Infrastructure & $\begin{array}{l}\text { Consumer } \\
\text { acceptance }\end{array}$ \\
\hline 1 & The Netherlands & 5 & 10 & 1 & 2 \\
\hline 2 & Singapore & 1 & 15 & 2 & 1 \\
\hline 3 & Norway & 7 & 2 & 7 & 3 \\
\hline 4 & United States & 9 & 3 & 8 & 6 \\
\hline 5 & Sweden & 10 & 6 & 6 & 4 \\
\hline 6 & Finland & 4 & 8 & 11 & 5 \\
\hline 7 & United Kingdom & 2 & 9 & 12 & 10 \\
\hline 8 & Germany & 6 & 4 & 13 & 13 \\
\hline 9 & United Arab Emirates & 11 & 14 & 5 & 7 \\
\hline 10 & Japan & 15 & 5 & 3 & 18 \\
\hline
\end{tabular}

Figure 5. Who is winning the race: national profiles (2019).

\section{Support for more AVs... but only up to a point}

Q. Broadly speaking, do you support the use of fully autonomous or partially autonomous vehicles? (\% Yes)
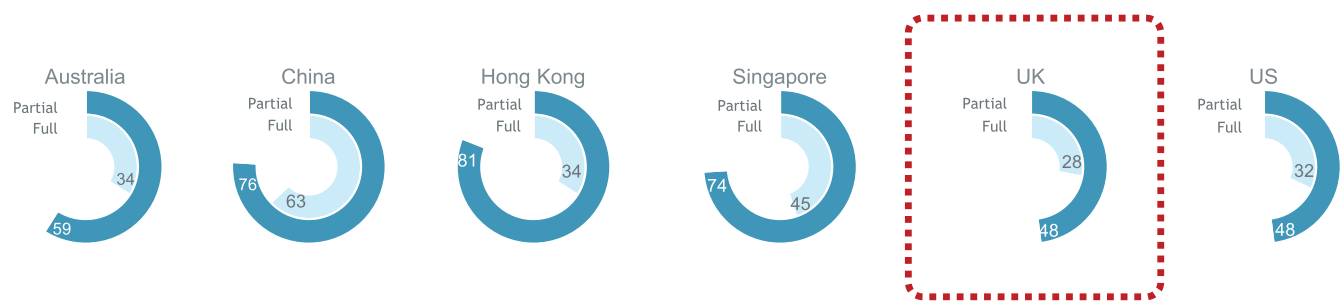

Australia: $n=1,066$

China: $n=878$

Hong Kong: $n=990$

Singapore: $n=1,027$

UK: $n=1,067$

US: $n=1,093$

Kennedys

Figure 6. Support for more AVs ... but only up to a point.

and the legislation. What it shows is that those countries who are winning the race recognise the importance of getting consumers on board in understanding what the technology is and what it means to them. It also indicates that those countries who are less developed in the technology around autonomous vehicles have a real opportunity to increase their ranking in terms of their readiness if they, too, can capitalise on consumer acceptance. 


\section{A question of trust: computer over human}

Q. Why do you not support the use of fully autonomous vehicles? (Top 4 reasons)

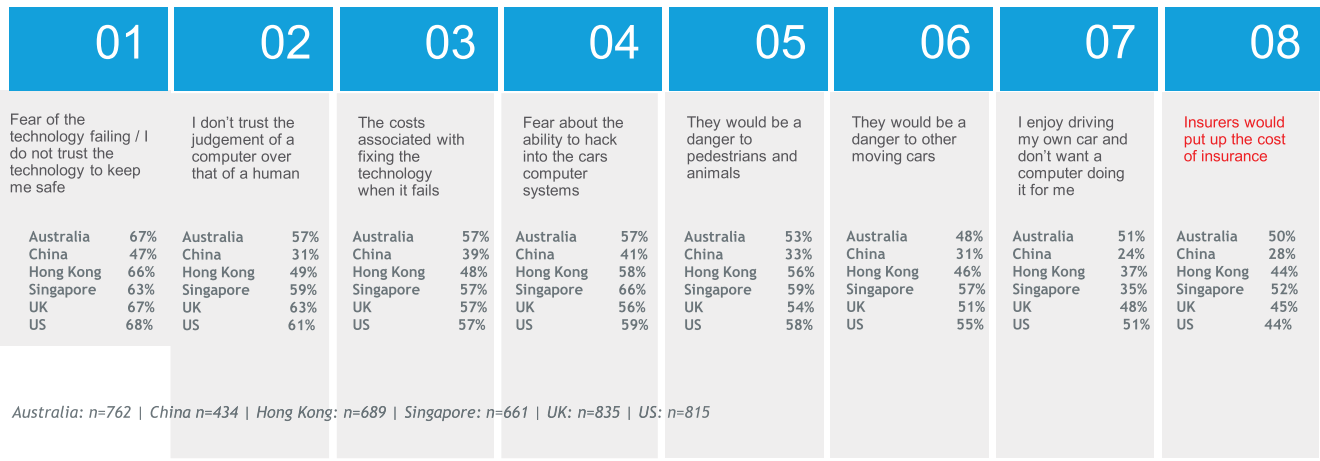

Kennedys

Figure 7. A question of trust: computer over human.

\section{A different future: insurance on-the-go, car ownership \& the daily commute}

Q. And finally, to what extent to you agree that the following describe how the world will look in the year 2039?

(\% somewhat/ strongly agree)

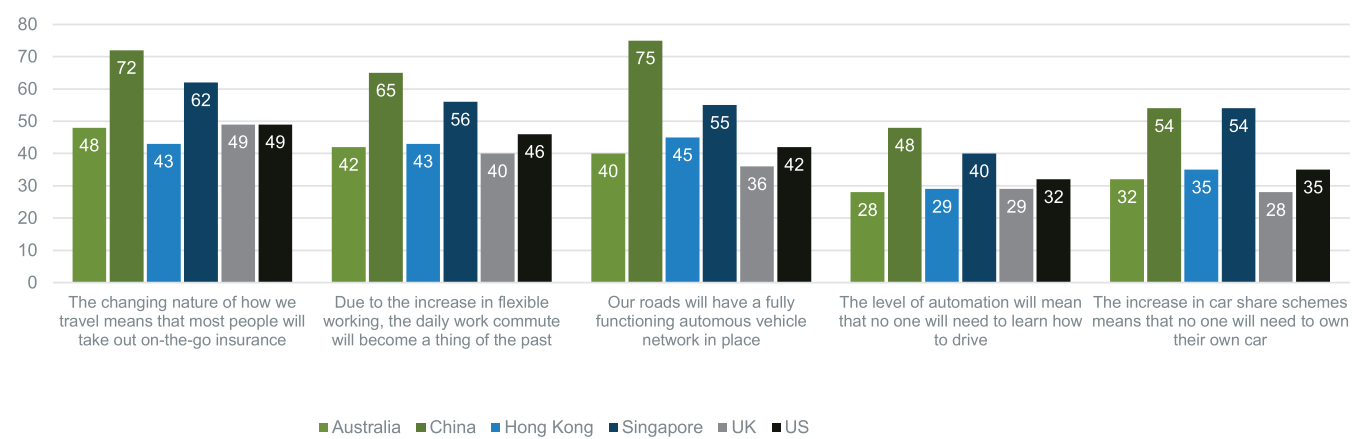

Figure 8. A different future: insurance on-the-go, car ownership and the daily commute.

Singapore is scoring the highest at the moment in terms of consumer acceptance. It is no real surprise because a huge amount of the population lives in the city at the moment and is surrounded by a test bed. They are already living and breathing the technology and what it means. Kennedys has been involved with a research project since 2017 looking into the sentiment around autonomous vehicles. What we did in 2017 was to look at what the UK consumer thought about all of this. We conducted a survey and it indicated that perhaps consumers were not quite as on 


\section{Autonomous Vehicles Working Group Understanding telematics is a good start}

Moving from Annual to more frequent data

- Understanding the dynamics of driving styles

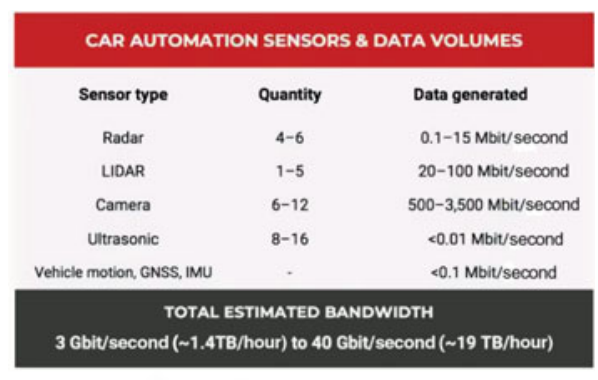

\section{But it is not the whole story ....}

- How do you process 1-20TB of data per vehicle per hour?

- How do you standardise across vehicle make/models?

- What data will we actually get (raw or KPI) ?

- What sensors are fitted / active?

- What systems are fitted / active?

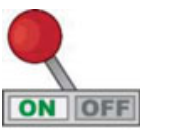

Figure 9. Understanding telematics is a good start.

board as the Government thought at that time. We repeated the exercise this year but this time we expanded the research. We looked for sentiment from both consumers as well as from business leaders. We did that across six survey countries: the UK, the US, Hong Kong, Singapore, China and Australia. We also expanded it beyond motor insurance because autonomous vehicle technology applies to the entire transport industry as well as logistics and all the other types of sectors that touch upon that. What did we find? See Figure 6.

Support is definitely there for autonomous vehicles, but public opinion varies hugely from country to country, including in relation to the different modes of transport. There are a number of factors at play and that includes sex and age and also where people live in the world. Perhaps it is no particular surprise that it is men and millennials and those living in urban environments who are more likely to support autonomous vehicles, and also those who consider themselves to have a higher understanding of the technology. There is support everywhere, but only up to a point. We have not yet reached the point where people have completely bought into the notion of a ghost vehicle where, effectively, you have got that pod vehicle with no human driver. For example in Hong Kong, whilst there was a high level of support for partially automated vehicles, $81 \%$ I believe, that level of support dropped quite significantly when we were talking about fully autonomous pod vehicles. China overall has the highest level of support for autonomous vehicles with nearly two thirds, 63\%, supporting that outcome. There is concern over ghost vehicles in the UK. We are a bit of a sceptical bunch when it came to looking into the detail of what people think about it. The US is not far behind us in that reluctance. Just 32\% in the US support full autonomous vehicles, and only $28 \%$ in the UK. Indeed, it was around about half of the population that we surveyed in the US and the UK that felt that road vehicle automation had already gone far enough. Currently just $4 \%$ globally feel that road vehicles should get to that point where they are able to drive themselves in all conditions without the option of having a human input and human override. See Figure 7.

Why is that? In a nutshell, it comes down to trust and control. Trust is among three of the four top reasons given by those who do not support the use of fully autonomous vehicles. It was the potential of the vehicle technology to fail, which is the biggest concern. That concern is highest in the US, with $68 \%$ citing this as the reason why they do not support the technology. The perceived 
costs, as we have touched upon in the first panel, are also among the top reasons for not supporting and being nervous about autonomous vehicles. That includes the cost of fixing the vehicle but it also includes the cost and the fear around what will happen with insurance. Many people still do not trust the judgement of a computer over that of a human, despite the irony as Niall (Edwards) pointed out that humans are in fact the biggest cause of accidents. We have still got some way to go in that regard. People want to be able to take control and they have concerns about what will happen when there is a switchover between computer and back to human. That in itself could lead to confusion and accidents and, in turn, questions around liability when something goes wrong. Benefits were appreciated. It was not all doom and gloom. Among the top types of benefits that people reported on the focus was very much around the potential that autonomous vehicles have to improve social mobility and financial independence, particularly for those who are either living in very remote areas or have disabilities.

The inclusion agenda is certainly one area I would expect to see policymakers get hold of and begin to craft a narrative around. Other benefits were the practical ones: the ability of the car to be able to park itself; less road rage; fewer arguments with the spouse; the ability to still be able to drive when you are tired; and also the recognition that there would be fewer accidents but that this would take time. Perception is very important at the moment. As the technology grows and improves, some of those trust and affordability issues will begin to resolve themselves. But for the time being the love of driving, particularly in countries like the UK and the US where we are fairly tied to our vehicles, is likely to hold appeal for quite some time among a fairly sizeable group of consumers. See Figure 8.

Looking to the future, we drill down into what people thought the landscape would look like in 20 years' time. It was evident that consumers think that the changing nature of how we travel will shift significantly. We probably won't need to learn to drive any more - most people will take out on-the-go insurance; and that the increases in the flexibility that driverless cars provide will probably mean that the daily work commute will become a thing of the past.

The UK, as I said, is the most resistant to change compared to, say, China, who already believe, in terms of over $50 \%$ of the population, that there will be a change in behaviour. They seem to be a lot keener for that to happen and are embracing that prospect. Indeed $75 \%$ of people in China and over half of people in Singapore agree that by 2039 the roads will have fully functioning autonomous vehicle networks in place. That falls to just $36 \%$ when we look at the UK.

In conclusion, public opinion across all aspects of AV technology is still very fluid. Those countries that encourage their populations to accept an understanding around the new technology will make significant progress in realising those opportunities. The consumer sentiment is going to be one of the vital pillars in the adoption of this technology. However there needs to be a balance. It is not just consumer acceptance. That needs to go hand-in-hand with a robust policy framework that encourages innovation as well as a strong track record in the technology and the high-quality road and digital infrastructure. The UK government realises that to some extent. If you look at the division of the current $\mathrm{R} \& \mathrm{D}$ projects, roughly $20 \%$ of those projects have an element of a consumer-acceptance focus within them. There is obviously an appreciation around the importance of getting consumers on board, but I suspect more will be needed as we go forward. Test beds will have an important part to play in encouraging and improving that sentiment.

Where there is scepticism, it is hard to speculate whether the lack of understanding leads to the scepticism or it is the scepticism that leads to a reluctance to gain understanding. That's probably more a comment around human behaviour. However, if the aim is to make safer and more efficient vehicles and roads, the advancement through technology is only one of the first steps. Building trust in autonomous vehicles represents a component part and also quite a significant challenge. Everyone that is involved needs to appreciate that automation is likely to set about a complete shake-up for those of us who are used to, and still enjoy, driving, which isn't going to go away quite yet. 
Mr A. K. Goldby, F.I.A.: On to the data science part and in terms of rating and how insurers are going to price business going forward, it is quite important to realise we have come a long way in the last century or so, from early vehicles powered by very small engines. It is fair to say that the Tesla is probably the most advanced of the commonly owned vehicles on the road today. That leads to some interesting things for motor rating. As we look back over what we have done over the last few decades, we have tended to price things on an annual basis using a mixture of vehicle factors, driver factors, policy factors and any third-party data sets we can get hold of. We have become pretty good at doing that. The rating is fairly good. It differentiates between risks pretty well. But the nature of all of the risks is changing. We are moving towards a situation where vehicles can be upgraded over the course of the policy year. It is not the same risk that you bought originally, or that you underwrote originally, and the data is very different.

You are not getting just that one touch point with the customer each year, when you are getting hold of the data. You can't keep that data similar for the whole year and then only change it at the next yearly update. You are now getting at least every second throughout the driving life of that vehicle. It is a little bit like telematics, on that basis, and it is crucially dependent on the software, the sensors and the actual data that you are getting. For a lot of actuaries, that is really interesting. They want all that data and it is going to be lots of fun. But you have to remember, there is quite a lot of that data. See Figure 9.

Current estimates are that these autonomous vehicles, the fully autonomous ones, are going to be generating up to 20 terabytes of data per hour that they are driving. That is quite a lot! If insurers look back at the volume of data they have collected over the last 10,20 and 30 years of all the policies that they have written, it is probably not quite as much as they would now get from one vehicle in a single year. If you ask your IT teams to look into that volume of data and produce information from it, this new data will take much longer to generate insights. You have got to find some way of understanding that data and distilling it into things that are useful.

Telematics is obviously a good start. We have all been doing this for a while. However, even if you understand how to use that behavioural data, that driving data, you are still nowhere near the full understanding of data that you need for these autonomous vehicles. For a start, what data are we actually going to get? Is it going to be standardised across vehicle models? Probably not. History says that OEMs like to do things their own way. As a result, the data they collect is likely to be very different across OEMs and almost certainly different across models within the OEM's stable. Someone needs to understand all of that. Also what are they actually going to provide to insurers? Is it going to be all the raw data from the vehicles? Again, probably unlikely. Is it going to be standardised into some key performance indicators that tell us what those vehicles are doing? That could be nicer. If it is KPIs, then it is probably easier to use, but it is probably also dumbed down, and maybe does not give you the level of granularity that you want. Beyond that, what sensors were fitted? At least you would hope that they are not going to change those very often. Once the vehicle comes out, do we even actually know what sensors are on it? What systems are active? What systems could be made active?

We kind of have that already. We know that there are vehicles with systems such as autonomous braking, or do we? Do we have a decent database saying that of all the vehicles that are currently sold, which vehicles have which safety features? It is coming. We know bits of it for the standard ones, but certainly not for the optional extras people have chosen. This would have to take this database to a whole new level, not only including what systems are fitted but also what they are currently capable of.

Then you have got this nasty transition. If we were able to jump just from normal cars, as we have them today, to fully autonomous level five, no steering wheel cars, we could probably find a way to rate them along the lines of product liability. But during the transition, you need to know who is driving, the machine or the human? You have got to have real-time indicators. We like to point fingers and say who was to blame. Is it the vehicle? Is it the driver? Did the person react fast enough to retake control of the vehicle if the vehicle handed back control? You need all those basic 
indicators as well as. Which version of the software? When was it last updated? Was it last night or did the owner choose not to allow it to update last night and would this make it the owner's "fault" rather than anything else? What happens next depends on the object you may hit. If the car in front of you slows down and stops before it hits anything, your autonomous vehicle will probably quite happily stop behind it.

If it pulls out at the last minute, what is the autonomous vehicle going to do? Just stay in lane and try to stop, or pull out? This is just a simple example but more complex rules are bound to be required. Which systems and rules are active at which time on the vehicle that you are insuring? Then we need to understand where these systems are going to be used. Everyone always says that using autonomous systems, or autonomous vehicles themselves, is going to make the roads much safer. I am not convinced. The places where most people are going to use these systems in the early days will be on motorways. Motorways are already our safest roads. They are not very risky at all. What we are talking about, with autonomous systems and a highway pilot that will drive you on a motorway, is making your life easier and giving you the ability to be more productive. You can work or use your phone while you are in the car. Is it going to make it that much safer though (assuming you were not going to try to work and drive at the same time without the system)? It will certainly make it more expensive because of the sensors on the vehicles, but I do not know that it will make it that much safer. Then there are other things such as the shift of ownership and the rise of peer-to-peer (P2P). Are we going to be insuring an annual policy like we do at the moment? Is it going to be very short term? Is it going to be product liability, or is it going to be personal liability? It becomes complicated, but the vehicle manufacturers have it worse.

The Chairman: I am now going to introduce our second panel. Nick Silk has worked at the Prudential Regulation Authority (PRA) since its formation, having joined the Financial Services Authority (FSA) in 2010. He is involved in work to understand the potential impact of connected and autonomous vehicles on the UK insurance market. Tom Sambrook is an underwriter at Hiscox. Tom is a member of the alternative risk underwriting team within Hiscox's London market, which writes a diverse portfolio of insurance and reinsurance risks across a variety of specialist coverages. Finally, Veekash (Badal) has come to rejoin us as part of this second panel.

The Chairman: Nick, can I talk about regulation for a second? Could regulation stifle innovation when it comes to AVs, and particularly when you think about insurers and their ability to compete in this space?

Mr N. Silk: We would hope not. We see the main barriers to the technology being the things that have been discussed in the first session around safety acceptance and so on. Our approach to regulation is that the principles will be the same under autonomy as they would be under manually driven vehicles. We would still have the same capital regime but the risks would be different. Some of them would be very challenging for firms. Obviously, we would expect them to understand and mitigate the risks around the transition we discussed earlier and particularly around things like cyber. We published research to show we are engaging with this. We are very keen to understand how the industry is mitigating risk. By having that dialogue, we reduce the risk of potentially going too far.

The Chairman: As actuaries, what should we be doing?

Mr Badal: The presentations we have seen today show that we have an exciting time ahead, both for those new to the profession as well as those who are more experienced. In the working party, we had been looking at five key work streams: data sites, insurance operations, infrastructure, product design and ethical issues. Autonomous vehicles provide a good case study, not just for the actuarial profession but also for the legal profession for what technology, automation and artificial intelligence might mean for these professions. A vast amount of data will be collected and we need to consider new product design and also the transition to these products. I do not think we should underestimate the transition from where we are now to where we might end up in 20 years' time, for example. That is going to be one of the biggest challenges. How do we move from motor insurance to product liability insurance and how that will turn out? 
Mr C. J. Gingell, F.I.A.: We have heard a lot about the technological and societal barriers that need to be overcome to get to autonomous vehicles. Do any of you envisage a risk that the right insurance coverage, or the right insurance at an achievable price, could at some point be a barrier to the wider rollout of autonomous vehicles?

Mr Badal: I think there is a big push for this. People will be spending billions of pounds on this development of autonomous vehicles. Whether we can keep up with it as a profession, or the regulation can keep up with it, I don't know. But I think it is a good question. Everybody will need to gear themselves up for the big change.

Mr Silk: I think it is too early to say because of the number of future risks around cyber, the transitional period, whether you can get an effective right of recovery and so on. Those are all difficult challenges. There is also a huge interest from the manufacturers to get insurance that allows their product to be taken up. You have seen Tesla trying to move into the space. I know they are making small steps. But I find it hard to believe that, ultimately, we expect these vehicles to be safer. From a prudential point of view, our understanding is that the risk profile will become lumpier. You might get far fewer of these small attritional claims, but maybe when things go wrong on the technology, you might get a mass hack. One of the updates goes wrong, and that could cause liquidity problems and the possibility of needing reinsurance. It will be possible to deal with it, but the profile of the risk will change rather than become unaffordable.

Mr T. Sambrook, F.I.A.: That is a key point about moving from personal lines to commercial. In reality, the reinsurance and the retro markets have got an abundant amount of capacity at the moment. This systemic event is what is going to concern those markets. The SME retail cyber market is going to have a far bigger aggregation that is incredibly difficult for them to monitor compared to the autonomous vehicle market. I do not see that being a hindrance to it.

Mr Goldby: We are going to be living in a really interesting time over the next few years because we have seen exactly the same with electric vehicles. People saw them as quite scary. Insurers tend to be quite risk averse. They see this new technology and worry it is going to explode or catch fire. We do not want to underwrite them, but maybe we will at a high price. Luckily, the UK market, being highly competitive, just forces the prices back down to something that is reasonable and bearable by consumers. I suspect we will see the same thing here as the technology advances, because it is not straight into level-five automation. If we ignore the commercial aspect, the product liability, and just concentrate on the personal liability, the standard motor insurance, at the moment prices will go up as the sensor technology gets more expensive and you fit more of them to the vehicles. Then it will start coming down again assuming people start seeing some of the benefits.

The Chairman: Deborah, you talked a lot about the customer or general public side of things. You also mentioned lobbying. Did you get any sense of the Government's understanding or future intentions?

Ms Newberry: Yes. Very much so. It was 2 years ago or so. The political agenda was slightly different from the one that we are facing at the moment. Government thinking was that autonomous vehicle technology was a priority, both in terms of realising the financial as well as the safety potential around it. Going through the lobbying exercise there was certainly no desire to overregulate. From our perspective, we are likely to see a slow burn when it comes to the legislation that is going to be needed on an ongoing basis. In a way it is reassuring because it is going to allow the technology to develop. On the other side, there was a lack of understanding at a policymaker level. There was a keenness to be able to put the UK forward, to say the UK will be at the forefront of this technology, which is probably going to be all the more important as part of saying our doors are open, post-Brexit. In terms of the technical aspects of what all this means, it wasn't really there. For example, there was definite confusion around the handover aspect between human and machine. All of that suggests, looking forward, there is real scope for satellite litigation. A mixed response to all of that. A willingness, yes, but a detailed understanding, no. It confirms that it is 
going to be for the industry to push what they want upon the Government when it comes to ironing out those finer details.

Mr H. E. Clarke, F.I.A.: I was interested by what you said about public acceptance. It seems to me we are leaving out human psychology in this discussion. We are actuaries, after all. We are moving from when the human has the control to when the human does not have the control. I would like to look at the aircraft industry. Aircraft, particularly commercial aircraft, have lots of people in them, and are engineered from a safety viewpoint to an incredibly high level compared to cars. One of the reasons is, when you get on an aircraft you do not have control. When you get into a car, you do have control. Even if you are not the driver, you can shout at the driver. Eventually public acceptance will start to push back and lead to demands for a level of safety regulation. After a few crashes and a few people have been killed, the resulting regulations will raise the costs quite dramatically by raising the bar much higher than people are considering at present.

Mr Sambrook: Certainly, the reputational element is going to be much more severe for those OEMs. There is a healthy level of scepticism about autonomous vehicles making better decisions than humans. As soon as you have incidents where people are dying, I am probably not going to want to get into my Tesla the next morning. Certainly, I am not going to go out and buy one. Those OEMs who have that, they might end up just losing market share and coming away from the market. From a products perspective, in opportunities where the insurance industry can play, where reputational risk products are coming more to the fore, they can definitely operate in this space. That is where I could see new products coming to the fore. With the insurance industry and actuaries, where can we engage more? As it goes into a commercial product type, can we interact with those CFOs and CROs, and work out what their risks are and how we can mitigate their balance sheets?

The Chairman: One of the interesting points for me is about how claims will work in the future. Talking about commercial insurance, when do you start to recover from the car manufacturers, or the software providers, and how does that give us a whole different claims environment?

Mr Badal: We have mentioned before about the data being collected, but operations will need to change if we move away from the motor insurance industry model now and to product liability. That data is being collected via the vehicles themselves. That is something that, say, the London market companies are not looking at presently. They are not looking at the future of what that will mean for them, and we need to look at whether their operations are geared up. It is an emerging risk for companies.

Mr Silk: An interesting point was made earlier about the Automated and Electric Vehicles Act. There will be this list of level fours and level fives. Insurers will have a right of recovery against the manufacturers of those vehicles if they go wrong. But we are not there yet, it is still hypothetical. There is a lot of good work going on about how to establish that right of recovery - how to get data that is able to prove which components went wrong. But just to plug the regulatory angle is always interesting to us. How could that go wrong? How can insurers always prove which component has failed? Is there a possibility of lengthy, costly litigation and so on? Again this brings us back to the lumpy risk profile. I do not want to paint a "doom and gloom" picture here, but it is an area that is of interest to us

Ms Newberry: Going back to the Government's thinking, there were two points to raise. There was a lack of understanding at policymaker level around the importance of data, or the access to data for insurers. The other point was a lack of desire to bring manufacturers into the frame in terms of shifting some of the onus of responsibility onto them when it comes to ensuring that safety-critical software is in place. At the moment the thinking is that it is up to the human driver to ensure it happens.

Mr R. B. Akhurst, F.I.A.: Coming back to this question of public acceptance. The police use the $85 \%$ rule to determine roughly what they think is the acceptable speed. For a city, it is $30 \mathrm{mph}$. If they try and introduce $20 \mathrm{mph}$, most people ignore that. The issue is, under an automated 
system, just by legislation or control, you can bring the average speed down from 30 to 20. People may wish to go faster, but the machine will not go faster. That potentially slows down city traffic even further, when it is already log-jammed. There is a big issue here. How do you get public acceptance of an acceptable level of risk, particularly when it can be ratcheted down very easily in future by legislation?

Mr Sandbrook: I am definitely not in the legislation element of the world, but my feeling is the OEMs are probably powerful enough to influence where that speed limit will sit. If the legislation moves vehicle speeds to an unacceptable level for the consumer, ultimately that product won't be desirable and their demand will fall away. There will be a compromise where the OEMs will work with legislators to come up with something that is reasonable from both sides.

Mr Goldby: We also need to differentiate between connected vehicles and autonomous vehicles. As soon as you are connected, theoretically, someone can control the maximum speed, or apply a speed limiter that is governed by location, even though the human driver is still in control. I do not think that would be accepted. You are going to be slowed down. You are not going to be able to drive as you want to. But once the vehicles are autonomous and you can do other things in the vehicles, while they are getting you from A to B, public perception might then be different.

The Chairman: We have touched on public scepticism, but there are some interesting things here: fewer accidents, fewer injuries and more productive use of time. Commuting turns into a question of "What can I use this time to do and enjoy myself, or work, or whatever it may be?" Traffic flow can be improved, more vehicle occupancy on the road. Why won't the public embrace this? Why won't they see all those good things and go rushing towards them, when the evidence was almost the reverse?

Ms Newberry: Certainly in the UK, it is going to come down to education and engagement. The statistics indicate that the UK is a little bit cynical, although there is nothing to say that it cannot be turned around. A good example is genetically modified crops. People think it is being imposed upon them. Education campaigns need to come from various stakeholders to promote the safety of it, and to allow people to feel they are part of the journey, so to speak.

Mr Badal: There are many benefits, as we have highlighted, but they are potential benefits at the moment. They have not been tested fully. We talk about the number of fatalities decreasing by $80 \%$, but it has not been tested. We are not just going to move from partial autonomy to autonomy. The general public will become more sceptical as there are some high-profile accidents. But over time, I can't see us taking a step back. It might not happen during our careers, but we will move towards this. My mother does not drive on the motorway. I have to do that sometimes. That is one benefit and there will be other benefits like that.

The Chairman: Do regulators have a part to play in this education, or do OEMs? Where does responsibility lie?

Mr Silk: We are trying to be as technologically neutral as possible. We are completely happy with it developing, but we focus entirely on insurers mitigating the risks. We obviously have an interest. One other element that was discussed earlier was the idea of mobility as a service. If you have the Uber equivalent, offering ride sharing, there is no need to buy a vehicle or buy your own insurance. You just pay on the spot and you have that availability and it is sufficiently cheap. People's qualms about safety, providing they are sufficiently well-prepared, will start to fall away, just because the product gets better. As a regulator, we definitely do not have a view. Broadly I accept it is a good thing, but we do not push one way or the other.

Mr M. Chavda: There has been a lot of focus around personal lines, but are there any industries or businesses that are pushing autonomous vehicles, such as Uber, or logistics businesses? Are they pushing autonomous vehicles more than the public?

Mr Badal: There is quite a bit of testing of these vehicles, more than people are aware of. The Government has been pushing this quite hard. Chris Grayling, Transport Secretary of UK Government, mentioned that there will be autonomous vehicles by 2020 . There is a lot more push 
for this than we think. The likes of Uber and Tesla are developing their products quite rapidly, faster than they will be accepted. There is a lot more development going on than we know about.

Ms Newberry: I would agree with that. Where I suspect the narrative will shift is that autonomous vehicles will become part of promoting the green agenda, whereas perhaps before it was the UK being seen at the forefront of the technology - driverless cars as well as drone technology. In answer to your question about other modes of transport, certainly in trains there is already consumer acceptance there. People have been using the Docklands Light Railway, or whatever it is in this country and overseas, probably without realising that they are getting onto a driverless vehicle. It comes back to the importance of perception. The idea of having those ghost vehicles, those ghost pods, is a big thing to overcome, but certainly in the case of trains, aeroplanes, aviation and marine shipping, the technology is already being applied and has been for quite some time.

The Chairman: Andy (Goldby), you talked a lot about data. One of my questions is, will insurers actually invest to understand all of this? Are we going to invest ahead of the curve, or will it be something that almost catches us out with how many terabytes of data that are going to start appearing? Are we going to put that investment in up front?

Mr Goldby: I doubt it, no. We are not very good at that, and we have to get the data first. We tend to wait, collect the data, see the claims against it, and then price for the reduction or increase after that. First, it would be important just to understand the data. I do not know how many insurers are advanced enough to understand the types of data that are coming from connected cars, let alone autonomous cars. They are getting much better. Some of them are still not very good. But when you start looking at the newer makes and models, things like the 100,000 Rivians that Amazon have just ordered to do all their deliveries, these are electric vehicles. Not autonomous, but full of ADAS systems. All of those ADAS systems will be supplying data in real time back to Rivian. Whether or not they will pass it on to insurers is another matter. Maybe there will need to be someone in the middle that turns it into a smaller, more key performance indicator data set. I do not know, but it is going to be one of these wait and watch. Keep speaking to OEMs, try and understand as best you can the data they can provide. It is going to be different through every OEM and almost certainly within different models within the OEM as well. It is going to be a bit of a nightmare, but very interesting.

The Chairman: Do you think the OEMs will try to monetise that to start to charge the industry?

Mr Goldby: Yes, of course they will.

Mr R. Kelsey, F.F.A.: One of the points I was going to make was about trucks. You don't know what is behind a truck, in the sense that you have a tractor and a trailer unit. Fitting extras to cheap trailers, which are going to get bashed, is rather expensive. There is a huge problem in doing autonomous trucks, unless you increase the cost by having lots of new trucks, which begs the question about modular features, and almost having a set-top box for a truck. Can you have device-independent, or open connected cars by having some sort of software or set-top box to drive a car?

Mr Goldby: I think potentially, yes, but it is going to be very difficult. Some of the sensors are going to be wired into the cars, so you can't just stick one of those little "spinny things" on the top. It depends, to a large extent, what the systems are designed to do. Dave (Baldwin) showed his picture of the sensors all around it, monitoring everything, but if all it is trying to do is work out what it could hit, then the sensors on the front might be okay. Do you need to see what is coming up behind you, if all you are interested in is what is in front of you? Lots of drivers do not care about what is behind them. Do autonomous vehicles need to? I would like to think they would, but maybe the cabs will just be slightly higher and see what they can.

Mr Kelsey: It goes back to the first instance of telematics, when you had to install something into a board, whereas now you can start using your phone. I am not proposing you put your phone on top of a car, but you could have the equivalent of a phone on each corner, or some sort of cheaper device. 
Mr Goldby: It depends entirely on what devices you want to use. There are plenty of sensors that are Bluetooth-enabled. Theoretically, you could put a Bluetooth-enabled sensor somewhere on the back. It would do the sensing ... and send the data ... on to the actual system within the main vehicle. How long that would last is another matter. If it is a camera-based system, not very long. If it is a simple sonic or radar type sensor, maybe a little bit longer. I do not think we are there yet, though. People like wires.

The Chairman: We have talked a bit about the manufacturers. Is there a world that says the Teslas, the Audis and so on provide your car with all the insurance and everything else bundled in, and insurance companies become pure capacity providers? Is that a vision of the future?

Mr Goldby: It is kind of there already. Most OEMs have partners that sell their insurance. Do customers buy them? No, not really. They like to go shopping on the aggregators and buy whatever is cheapest. So, in theory, yes. In practice, they could do it already. They don't want to underwrite the risk. Even if they did go down that route, they would want an insurer to do the underwriting for them.

Mr Sanbrook: I agree with that. One of the key points is the regulatory burden that would come from turning them into carriers and absorbing their own risk. Where that has happened in the past, they quickly realised that is not a space they want to be in. They bring another insurer to sit in front of them.

Ms N. Li: Interesting point on the OEMs probably not wanting to become a carrier, but what about OEMs becoming an aggregator or distributer? They can potentially become an aggregator.

Mr Sambrook: Yes, I could see that. At that point, you are effectively turning it into an Managing General Agent (MGA) model, and that could be the case. There are lots of MGAs, obviously moving away from the OEM space, who do that already and have aggregators. They just have a panel of capacity that sits behind them. I could see OEMs doing that. They are certainly sophisticated enough, from a data perspective, to be able to do that pretty well.

The Chairman (closing the discussion): Thank you to those who have taken part in both of the panels today, and for the presentations, and thank you also for the questions from the audience.

Cite this article: Autonomous vehicles and impacts of the wider insurance industry - Sessional Meeting Discussion. British Actuarial Journal. https://doi.org/10.1017/S1357321720000161 